九州大学学術情報リポジトリ

Kyushu University Institutional Repository

\title{
Developmental Biology of Liriomyza chinensis (Diptera: Agromyzidae) on Onion
}

Tran, Dang Hoa

Graduate School of Bioresource and Bioenvironmental Sciences, Kyushu Unviersity

Takagi, Masami

Faculty of Agriculture, Kyushu Unviersity

https://doi.org/10.5109/4650

出版情報: 九州大学大学院農学研究院紀要. 50 (2)，pp. 375-382，2005-10-01. Faculty of Agriculture, Kyushu University

バージョン：

権利関係 : 


\title{
Developmental Biology of Liriomyza chinensis (Diptera: Agromyzidae) on Onion
}

\author{
Dang Hoa TRAN ${ }^{1}$ and Masami TAKAGI* \\ Laboratory of Insect Natural Enemies, Division of Biological Control, Department of \\ Applied Genetics and Pest Management, Faculty of Agriculture, Kyushu University, \\ Fukuoka 812-8581, Japan \\ (Received June 15, 2005 and accepted July 26, 2005)
}

\begin{abstract}
The stone leek leafminer, Liriomyza chinensis (Kato), has become a serious pest on Allium spp. in several Asian countries. However, knowledge concerning the biology of $L$. chinenis, which affect development of control programs, is still limited. The biology of the leafminer on onion was investigated at a constant temperature of $25^{\circ} \mathrm{C}$ and a photoperiod of 16L: 8D. To distinguish different larval instars, some morphological characteristics such as the length of mouth hooks, cephalopharyngeal skeleton, body and mine were measured. The length of mouth hooks and cephalopharyngeal skeleton of first, second and third instars were $0.021 \mathrm{~mm}$ and $0.089 \mathrm{~mm}, 0.054 \mathrm{~mm}$ and $0.165 \mathrm{~mm}$, and $0.092 \mathrm{~mm}$ and $0.261 \mathrm{~mm}$, respectively. Developmental time for the immature stages was 22.6 days; pupal development lasted slightly longer than the combined egg and larval stages. The females laid a mean of 108 eggs and fed on 1013.9 punctures during an average lifespan of 9 days. Feeding and fecundity peaked at age 5 days. The intrinsic rate of natural increase $\left(r_{m}\right)\left(\right.$ day $\left.^{1}\right)$, net reproduction $(R o)$, and generation time $(T)$ (day) were $0.099,14.3$ and 27.1 , respectively.
\end{abstract}

\section{INTRODUCTION}

The genus Liriomyza contains more than 300 species which are widely distributed in the New and Old Worlds but most occur naturally in the temperate regions (Parrella, 1987). Approximately 23 species of Liriomyza have been reported as being economically important (Spencer, 1973). As major pests, Liriomyza spp. are the targets of chemical and biological control programs (Murphy and LaSalle, 1999). Biological control of Liriomyza leafminers by parasitoids can be very effective and give economic control in some vegetable crops (Waterhouse and Norris, 1987; Minkenberg, 1990; Murphy and LaSalle, 1999). To evaluate the effectiveness of parasitoids for biological control in pre-introduction study, data on the development and reproduction of leafminers and their parasitoids are necessary (Minkenberg and van Lenteren, 1987).

The stone leek leafminer Liriomyza chinensis (Kato) has become a serious pest on Allium spp. in China, Japan, Malaysia, Singapore, Thailand (Spencer, 1973, 1990; Chen et al., 2003), Korea (Hwang and Moon, 1995), Vietnam (Andersen et al., 2002), and Taiwan (Shiao, 2004). However, knowledge concerning the biology of L. chinensis, which affect development of control programs, is still limited. The objectives of the present studies

\footnotetext{
${ }^{1}$ Laboratory of Insect Natural Enemies, Division of Biological Control, Department of Applied Genetics and Pest Management, Graduate School of Bioresource and Bioenvironmental Sciences, Kyushu University

* Corresponding author (E-mail: mtakagi@agr.kyushu-u.ac.jp)
} 
were to determine larval morphology, developmental time for egg, larval, and pupal stages and adult feeding, fecundity, and longevity of $L$. chinensis on onion. The knowledge of the basic biological characteristics of this leafminer is of fundamental importance for development of biological control strategies.

\section{MATERIALS AND METHODS}

\section{Insect rearing}

Liriomyza chinensis used for the present study was originated from a culture reared by the Fukuoka Agricultural Research Center, Fukuoka, Japan. The leafminer was reared on Japanese bunching onion, Allium fistulosum L. Seeds of this plant were sown in a tray $(20 \mathrm{~cm} \times 60 \mathrm{~cm} \times 15 \mathrm{~cm})$. Two months after germination, a single plant was transplanted in a plastic pot $(9 \mathrm{~cm}$ in diameter). A tray $(32 \mathrm{~cm} \times 44 \mathrm{~cm} \times 6 \mathrm{~cm})$ containing 15 potted plants was placed in a small greenhouse at $20 \pm 5^{\circ} \mathrm{C}$ and $60 \pm 10 \%$ humidity.

Six potted plants at 2-3 leaves stage were exposed to 50 mixed sex $L$. chinensis adults in a plastic cage $(45 \mathrm{~cm} \times 30 \mathrm{~cm} \times 25 \mathrm{~cm})$ covered with a fine nylon mesh. After an exposure for $24 \mathrm{~h}$, the flies were removed and these plants were maintained in an environmental chamber at a constant temperature of $25^{\circ} \mathrm{C}$ and a photoperiod of $16 \mathrm{~L}$ : $8 \mathrm{D}$ until all leafminer larvae feeding on the plants reach pupae. Before incubation, the upper opening of each pot was covered with a piece of reversed funnel-shaped filter paper $(11 \mathrm{~cm}$ in diameter) to prevent leafminer larvae from pupating in the soil. The pupae were transferred to petri dishes $(9 \mathrm{~cm}$ in diameter) containing damp soil and maintained at the same condition to gain adult leafminers.

\section{Larval instar distinguishing}

Six potted plants were caged and exposed to 50 mixed sex $L$. chinensis adults in a plastic cage $(45 \mathrm{~cm} \times 30 \mathrm{~cm} \times 25 \mathrm{~cm})$ covered with a fine nylon mesh for an oviposition access period of $2-4 \mathrm{~h}$. After oviposition access period, the plants were removed and held in an incubator at a constant temperature of $25^{\circ} \mathrm{C}$ and a photoperiod of $16 \mathrm{~L}: 8 \mathrm{D}$. To distinguish the three larval stages occurring within leaves, some morphological characteristics such as the length of mouth hooks, body and mine were measured. The measurement of the length of the mouth hooks and cephalopharyngeal skeleton was made in the same manner as described by Petitt (1990). Few days after oviposition, when the mines became visible on the plants, larvae were collected from primary leaves every $12 \mathrm{~h}$ and preserved in a 70\% ethanol: water mixture until examination. A total of 201 larvae were dissected and examined under a stereomicroscope (SMZ1000, Nikon Intech Co., LTD., Japan).

\section{Immature development}

Six plants were infested with $L$. chinensis using the method described above and subsequently placed in an environmental chamber at a constant temperature of $25^{\circ} \mathrm{C}$ and a photoperiod of 16L: 8D. Eggs, which became clearly visible after a few days, were individually located and marked by circling that area of the leaf with a felt-tip pen under a microscope. Egg hatch was determined by inspecting the leaves with the microscope every 12 hours. Only the larvae that had hatched at the same time were monitored for 
larval development time calculation. Larvae that hatched at different time were killed with an insect pin. Larval instars were distinguished using the method described above. The end of larval development was assessed by collection of pupae from the plants at a 12 hours interval. The pupae were individually placed in petri dishes $(6 \mathrm{~cm}$ in diameter $)$ containing damp soil and maintained at the same experimental conditions. Adult emergence for each pupa and its sex were daily recorded to determine mean development time.

\section{Longevity, feeding and fecundity}

Pupae were randomly removed from the insect rearing cages and placed singly in petri dishes $(6 \mathrm{~cm}$ in diameter) containing damp soil and maintained in the environmental chamber. On the day of adult emergence, one female and two males were released into a plastic cage $(35 \mathrm{~cm} \times 20 \mathrm{~cm} \times 25 \mathrm{~cm})$ containing one onion potted plant. The cages were made of transparent plastic with openings covered with a fine nylon mesh for air circulation. Honey was not provided to the flies. These were kept in environmental chambers at a constant temperature of $25^{\circ} \mathrm{C}$ and a photoperiod of $16 \mathrm{~L}$ : 8D. Plants were exchanged daily and dead males were replaced with newly emerged males until the females died. The number of feeding punctures and visible eggs were daily counted, and longevity of females was determined.

\section{Rate of population increase}

The plants daily exposed to female flies were maintained in the environmental chambers until all leafminer larvae reach pupae. The pupae were individually placed in petri dishes $(6 \mathrm{~cm}$ in diameter) containing damp soil and maintained at the same experimental condition. The fly offspring emerged for each female at a defined age were daily recorded and sexed. The net reproduction rate $\left(R_{0}\right)$, mean generation time $(T)$ and intrinsic rate of natural increase $\left(r_{m}\right)$ were calculated according to the equations given by Birch (1948):

$$
R O=\sum l_{x} m_{x} ; T=\sum x l_{x} m_{x} / \sum l_{x} m_{x} ; \sum\left(\exp \left(-r_{m} x\right) l_{x} m_{x}\right)=1
$$

where, $x$ is female age, $l_{x}$ is the proportion of females surviving to age $x, m_{x}$ is the expected number of daughters produced per female alive at age $x$.

\section{RESULTS}

\section{Distinguishing between larval instars}

Distinctive separation among the three larval instars of L. chinensis was possible using their morphological variables such as length of mouth hook, cephalopharyngeal skeleton, body and mine (Table 1). The mean length of mouth hooks and cephalopharyngeal skeleton of first, second and third instars were $0.021 \mathrm{~mm}$ and $0.089 \mathrm{~mm}, 0.054 \mathrm{~mm}$ and $0.165 \mathrm{~mm}$, and $0.092 \mathrm{~mm}$ and $0.261 \mathrm{~mm}$, respectively. There was no overlaps in length of mouth hook and cephalopharyngeal skeleton among three instars (Fig. 1)

\section{Immature development}

The developmental time for immature stages was 22.6 days (Table 2). The eggs 
Table 1. Length (mm, Mean \pm SE) of mouth hooks, cephalopharyngeal skeleton, body and mine of $L$. chinensis larvae at $25^{\circ} \mathrm{C}$.

\begin{tabular}{lcccccc}
\hline \multicolumn{1}{c}{ Larval instar } & First & $\mathrm{N}$ & Second & $\mathrm{N}$ & Third & $\mathrm{N}$ \\
\hline Mouth hook & $0.021 \pm 0.0003$ & 42 & $0.054 \pm 0.0004$ & 103 & $0.092 \pm 0.0012$ & 56 \\
& $(0.018-0.026)^{\mathrm{a}}$ & & $(0.042-0.064)^{\mathrm{a}}$ & & $(0.076-0.113)^{\mathrm{a}}$ & \\
Cephalopharyngeal & $0.089 \pm 0.0014$ & 42 & $0.165 \pm 0.0018$ & 103 & $0.261 \pm 0.0037$ & 56 \\
skeleton & $(0.065-0.114)$ & & $(0.126-0.203)$ & & $(0.213-0.314)$ & \\
Body & $0.685 \pm 0.023$ & 34 & $1.429 \pm 0.039$ & 105 & $2.61 \pm 0.066$ & 61 \\
& $(0.425-0.97)$ & & $(0.831-2.35)$ & & $(1.68-3.63)$ & \\
Mine & $6.4 \pm 0.59$ & 21 & $12.2 \pm 0.89$ & 21 & $37.2 \pm 2.68$ & 21 \\
& $(2.3-13.9)$ & & $(5.2-19.2)$ & & $(10.8-63.9)$ & \\
\hline
\end{tabular}

${ }^{a}$ (Range)

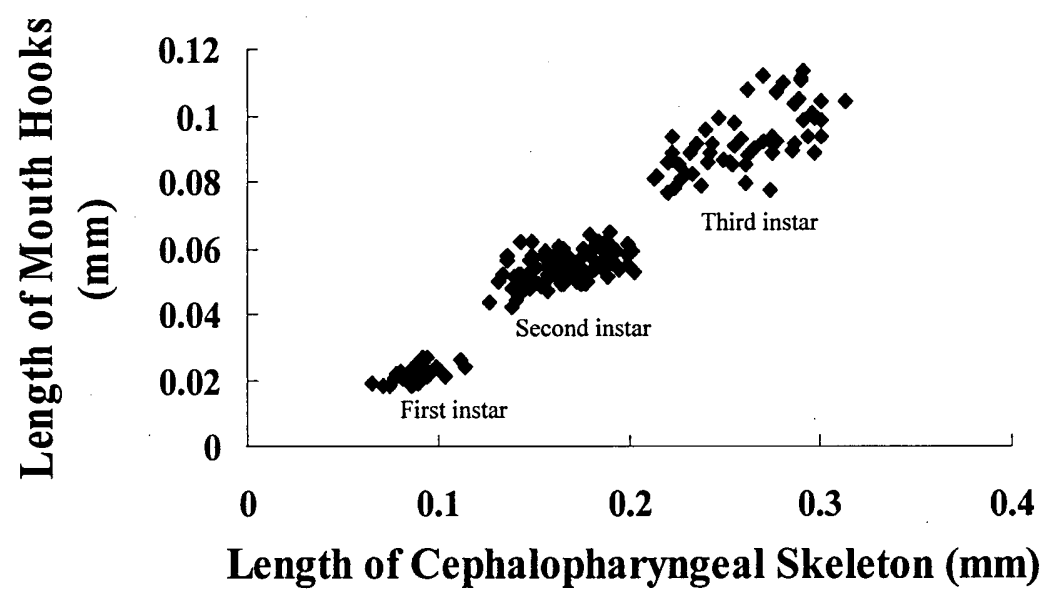

Fig. 1. Relationship between lengths of mouth hooks and cephalopharyngeal skeleton for first, second and third instars of $L$. chinensis.

Table 2. Developmental time (day) of L. chinensis at $25^{\circ} \mathrm{C}$.

\begin{tabular}{lrcc}
\hline \multicolumn{1}{c}{ Stage } & Mean \pm SE & Range & $\mathrm{N}$ \\
\hline Egg & $3.4 \pm 0.06$ & $2.5-4$ & 50 \\
First instar & $1.6 \pm 0.08$ & $1-2$ & 35 \\
Second instar & $1.7 \pm 0.05$ & $1-2$ & 72 \\
Third instar & $2.3 \pm 0.07$ & $1.5-3$ & 61 \\
Pupa & $13.6 \pm 0.09$ & $12-16$ & 68 \\
Total & $22.6 \pm 0.19$ & $20.5-24$ & 35 \\
\hline
\end{tabular}


hatched 2.5 to 4 days after oviposition. The first instar fed on the leaves, and mounted into the second instars after 1 to 2 days. The second instar larvae lasted for 1 to 2 days, then mounted into the third instars. The final instar, after 1.5 to 3 days of its mounting, cut their way out of mines, and finally fell to the ground for pupation. The pupal stage lasted for an average of 13.6 days.

\section{Longevity, feeding and fecundity}

The females laid a mean of 108 eggs and fed on 1013.9 punctures during an average lifespan of 9 days (Table 3). While the pre-oviposition period lasted for 2.4 days after

Table 3. Mean feeding (no. punctures), fecundity (visible eggs), longevity (day), feeding rate (no. punctures/day), oviposition rate (viable eggs/day), ratio of eggs and feeding punctures and pre- and post- oviposition periods (day) of L. chinensis at $25^{\circ} \mathrm{C}$.

\begin{tabular}{lc}
\hline & Mean \pm SE (range) \\
\hline Feeding & $1013.9 \pm 199.1(191-2592)$ \\
Longevity & $9 \pm 1.1(4-14)$ \\
Feeding rate & $104.7 \pm 12.1(47.8-185.1)$ \\
Fecundity & $108 \pm 22.3(17-281)$ \\
Oviposition rate & $11.7 \pm 1.9(4.2-25.5)$ \\
Eggs/feeding punctures & $0.11 \pm 0.02(0.06-0.21)$ \\
Pre-oviposition & $2.4 \pm 0.7(0-8)$ \\
Post-oviposition & $0.6 \pm 0.2(0-2)$ \\
$\mathrm{N}$ & 11 \\
\hline
\end{tabular}

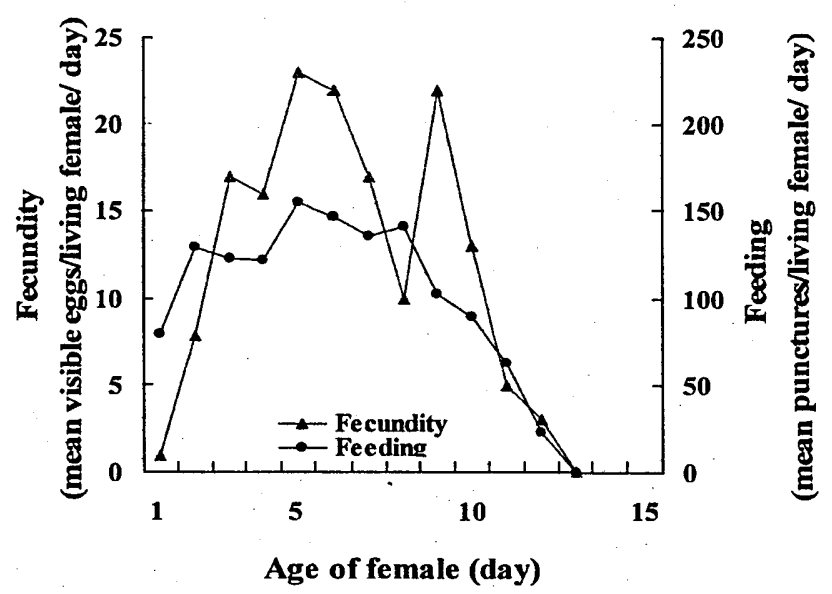

Fig. 2. Gross reproduction and feeding of $L$. chinensis at $25^{\circ} \mathrm{C}$ 
emergence, the females stopped laying eggs (post-oviposition) just about an average of 0.6 day before death. Mean feeding rate (number of punctures a day) and mean oviposition rate (number of visible eggs a day) were 104.7 and 11.7 , respectively.

The oviposition rate showed a slow increase with a peak at day 5 , after which a slow decrease followed until females' death (Fig. 2). There was a similar tendency in oviposition and feeding activities. Feeding and fecundity had a correlation coefficient (Fisher's $\mathrm{r}$ to $\mathrm{z}$ transformation) of $0.58(\mathrm{~N}=11 ; P<0.05 ; Z=1.89)$, feeding and longevity of $0.82(\mathrm{~N}=11, P<0.01 ; Z=3.26)$, and fecundity and longevity of $0.52(\mathrm{~N}=11 ; P>0.05$; $Z=1.64$ ). Partial correlation between feeding and fecundity was 0.32 , and between feeding and longevity 0.74 .

\section{Rate of population increase}

The population growth of $L$. chinensis at $25^{\circ} \mathrm{C}$ was shown by the intrinsic rate of increase value $\left(r_{m}\right)$ of 0.099 day $^{1}$. The generation time $(T)$ was 27.1 days. A population may multiply 14.3 times per generation.

\section{DISCUSSION}

In the present study, some morphological characteristics such as the lengths of mouth hook, cephalopharyngeal skeleton, body and mine were measured to distinguish the three larval stages of $L$. chinensis occurring within onion leaves (Table 1 ). Comparison of the morphological variables among three instars of $L$. trifolii revealed that the length of mouth hooks was a reliable character to distinguish the larval instars (Minkenberg, 1999). However, a slight overlap in the size ranges of mouth hook structures for three instars of $L$. huidobrensis was recorded, but this potential source of error can be overcome by using measurements of both the mouth hooks and the cephalopharyngeal skeleton to accurately distinguish between instars (Head et al., 2002). Our study identified that no overlap in variation of mouth hook and cephalopharyngeal skeleton lengths occurred among three instars of $L$. chinensis (Fig. 1). Therefore, measuring the sizes of mouth hook and cephalopharyngeal skeleton will enable the three instars to be easily distinguished.

The efficacy of chemical and biological control agents frequently varies between different instars of a target pest (Head et al., 2002). A previous study on insecticide susceptibility of $L$. trifolii suggested that most insecticides were more efficacious against the first instar than the third instar (Parrella et al.,1982). Petitt and Wietlishbach (1993) found that parasitization efficiency of Opius dissitus (Hym: Braconidae) was higher when second and third instars of $L$. sativae were provided to the parasitoid as compared to the first instars. Therefore, data indicating the developmental time of $L$. chinensis (Table 2) can be used in population sampling record to optimize control decisions by identifying when the maximum proportion of susceptible individuals are present, facilitating improved timing of application of control measures.

The damage caused by $L$. chinensis to onion plants is very similar to other Liriomyza species: larvae mine and feed within the leaves, and females produce feeding punctures on the leaves with their ovipositor. The adults feed from all punctures, regardless of whether or not they are used for oviposition (Bethke and Parrella, 1985; 
Parrella, 1987). The feeding activity of a female was age-dependent and increased sharply during the early day of her life to a peak at day 5 , after which feeding rate declined with age (Fig. 2). Females made an average of 1013.9 punctures during her lifespan (Table 3). Leaf punctures can reduce photosynthesis and may kill young plants (Elmore and Ranney, 1954; Parrella et al., 1985). Therefore, leaf puncturing and feeding by adult Liriomyza undoubtedly serve an important role in host plant loss assessment (Parrella, 1987).

The feeding punctures can also serve as oviposition sites. Egg laying begins within 2.4 days after female emergence and peaks at day 5, decreasing thereafter until females' death (Fig. 2). The females laid a mean of 108 eggs during an average lifespan of 9 days (Table 3). Fecundity and longevity of Liriomyza females are strongly related to food resources (Parella, 1987). Direct access to honey greatly enhances fecundity and longevity of $L$. trifolii (Zoebisch and Schuster, 1987). However, sugar sources were not likely to present under commercial onion greenhouse conditions, they were not provided to the flies in this study. The present study indicates significant correlation coefficients between feeding and fecundity, and feeding and longevity in L. chinensis females. This result is consistent with research in The Netherlands indicating that feeding on plant sap was of importance both for the production of egg and for the prolongation of life span (Minkenberg, 1999).

The average net reproduction rate $(R o)$ suggests that $L$. chinensis population would increase 14.3 times during each generation. The average intrinsic rate of natural increase was 0.099 per individual per day at $25^{\circ} \mathrm{C}$. Although such data are necessary to predict the reproductive potential of $L$. chinensis population in greenhouses and open fields, further experiments at different temperature levels are required, since Minkenberg (1999) showed that the net reproductive rates of $L$. trifolii and $L$. bryoniae were variable with temperatures. To predict population dynamics of $L$. trifolii under field conditions at fluctuating temperatures, interpolation from data measured in the laboratory at constant temperatures is only possible when the life history variables react instantaneously to temperature (Minkenber, 1999)

\section{ACKNOWLEDGMENTS}

We thank Mr. Hiroyuki Takemoto (Fukuoka Agricultural Research Centre) for providing $L$. chinensis. This work was supported in part by a Grand-in-Aid from the Japanese Society for the Promotion of Science and Technology (No. 15208007).

\section{REFERENCES}

Andersen, A., E. Nordhus, V. T. Thang, T. T. T. An., H. Q. Hung and T. Hofsvang 2002 Polyphagous Liriomyza species (Diptera: Agromyzidae) in vegetables in Vietnam. Trop. Agric. (Trinidad),79: 241-246

Bethke, J. A and M. P. Parrella 1985 Leaf puncturing, feeding and oviposition behavior of Liriomyza trifolii. Entomol. Exp. Appl., 39: 149-154

Chen, X. X., X. Y. Lang, Z. H. Xu, J. H. He and Y. Ma 2003 The occurrence of leafminers and their parasitoids on vegetables and weeds in Hangzhou area, Southeast China. BioControl, 48: 515-527

Elmore, J. C and C. A. J. Ranney 1954 Injury to pepper plants by the pea leafminer. J. Econ. Entomol., 47: $357-358$ 
Head, J., K. F. A. Walters and S. Langton 2002 Utilisation of morphological features in life table studies of Liriomyza huidobrensis (Dipt., Agromyzidae) developing in lecttuce. J. Appl. Ent., 126: 349-354

Hwang, C. Y. and H. C. Moon 1995 Effect of temperature on the development and fecundity of Liriomyza chinensis (Diptera: Agromyzidae). Korean J. Appl. Entomol., 34: 65-69 (in Korean with English summary)

Minkenberg, O. P. J. M. 1999 On seasonal inoculative biological control. Wageningen Agricultural University, The Netherlands, PhD thesis. $230 \mathrm{pp}$

Minkenberg, O. P. J. M. and J .C. Van Lenteren 1987 Evaluation of parasitic wasps for the biological control of leafminers, Liriomyza spp., in greenhouse tomatoes. Bull. IOBC/WPRS 10: 116-120

Murphy, S. T. and J. LaSalle 1999 Balancing biological control strategies in the IPM of New World invasive Liriomyza leafminers in field vegetable crops. Biocont. News Inf., 20: 91-104

Parrella, M. P 1987 Biology of Liriomyza. Ann. Rev. Entomol., 32: 201-224

Parrella, M. P., K. L. Robb and P. Morishita 1982 Response of Liriomyza trifolii (Diptera: Agromyzidae) larvae to insecticides, with notes about efficacy testing. J. Econ. Entomol., 75: 1104-1108

Parrella, M. P., V. P. Jones, R. R. Youngman and L. M. Lebeck 1985 Effect of leaf mining and leaf stippling of Liriomyza spp. on photosynthetic rates of chrysanthemum. Ann. Entomol. Soc. Am., 78: $90-93$

Petitt, F. L. 1990 Distinguishing larval instars of the vegetable leafminer, Liriomyza sativae (Diptera: Agromyzidae). Florida Entomol., 73: 280-286

Petitt, F. L. and D. O. Wietlisbach 1993 Effects of host instar and size on parasization efficiency and life history parameters of Opius dissitus. Entomol. Exp. Appl., 66: 227-236

Shiao, S. F 2004 Morphological diagnosis of six Liriomyza species (Diptera: Agromyzidae) of quarantine importance in Taiwan. Appl. Entomol. Zool., 39: 27-39

Spencer, K. A. 1990 Host specialization in the world Agromyzidae (Diptera). Series Entomologica. Kluwer Acad. Pub. Dordrecht

Spencer, K. A. 1973 Agromyzidae (Diptera) of economic importance. Dr. W. Junk B. V., Publishers, The Hague

Waterhouse, D. F. and K. R. Norris 1987 Biological control: Pacific prospects. Melbourne, Australia, Inkata Press

Zoebisch, T. G. and D. J. Schuster 1987 Longevity and fecundity of Liriomyza trifolii (Diptera: Agromyzidae) exposed to tomato foliage and honeydew in the laboratory. Environ. Entomol., 16: 1001-1003 